\title{
Nanoparticle sterilization methods for biomedical applications in animals
}

\author{
Galicia-González, Reyna Argelia ${ }^{1}$; Ortega-Cerrilla, María Esther ${ }^{1 *}$; Nava-Guellar, Guahutémoc ${ }^{2}$; \\ Miranda-Jiménez, Leonor ${ }^{1}$; Ramírez-Mella, Mónica ${ }^{3}$, Ayala-Rodríguez, Julio Miguel ${ }^{1}$ \\ ${ }^{1}$ Colegio de Postgraduados Campus Montecillo, Carretera México-Texcoco km 36.5, Montecillo, Texcoco, \\ Estado de México, México, G.P. 56230. \\ 2 Universidad Nacional Autónoma de México, Facultad de Medicina Veterinaria y Zootecnia, Av. Universidad \\ No. 3000, Giudad Universitaria, Coyoacán, Giudad de México, México, G.P. 04510. \\ 3 Colegio de Postgraduados Campus Campeche, Carretera Haltunchén-Edzná, Champotón, Campeche, \\ México, C.P. 24450. \\ * Correspondence: meoc@colpos.mx
}

\begin{abstract}
Objective: To review different nanoparticle sterilization methods for their use in biomedical applications in animals.

Approach: Sterilization is used to obtain a microorganism-free product without altering its physicochemical characteristics during its preparation, storage, or administration route. This review explores different sterilization methods and their advantages and disadvantages on the nanoparticle level.

Study limitations/implications: Nanoparticles are used in animal production, including their parenteral administration. Therefore, establishing the characteristics of different technologies applied to sterilize nanoparticles is essential to ensure the delivery of sterile products preventing health risks.

Conclusions: The use of nanotechnology in livestock production offers several advantages for animal nutrition, reproduction, and health, among other things. When nanoparticles must be sterilized, choosing the most suitable method is essential. This depends on the amount of product and its compound type because each technique has specific requirements that must be taken into account to be ready for potential changes in the structure and availability of the final product.
\end{abstract}

Keywords: Animals, Parenteral application, Nanoparticles, Sterilization.

Gitation: Galicia-González, R. A., Ortega-Cerrilla, M. E., Nava-Cuellar, C., Miranda-Jiménez, L., RamírezMella, M., \& Ayala-Rodríguez, J. M. (2021). Nanoparticle sterilization methods for biomedical applications in animals. Agro Productividad. https://doi. org/10.32854/agrop.vl4i12.1844

Editor in Chief: Dr. Jorge Cadena Iñiguez

Received: January 1, 2020. Accepted: November 18, 2021. Published on-line: December 20, 2021

This work is licensed under a Creative Commons Attribution-NonCommercial 4.0 International license.

\section{INTRODUGTION}

The word "nano" comes from the Latin nanus, which means dwarf. Nanoparticles come in different sizes and react in different conditions. They can measure between 1 and 100 nanometers. Nanoparticles are divided into organic, inorganic, emulsions, and nanoclays, depending on their chemical composition. Nanoparticles have been used in animal production to provide minerals, vitamins, proteins, and other essential nutrients (Bunglavan et al., 2014). They are also used to improve intestinal health, regulate gut microbiota, maintain blood homeostasis, increase immune response, and improve semen

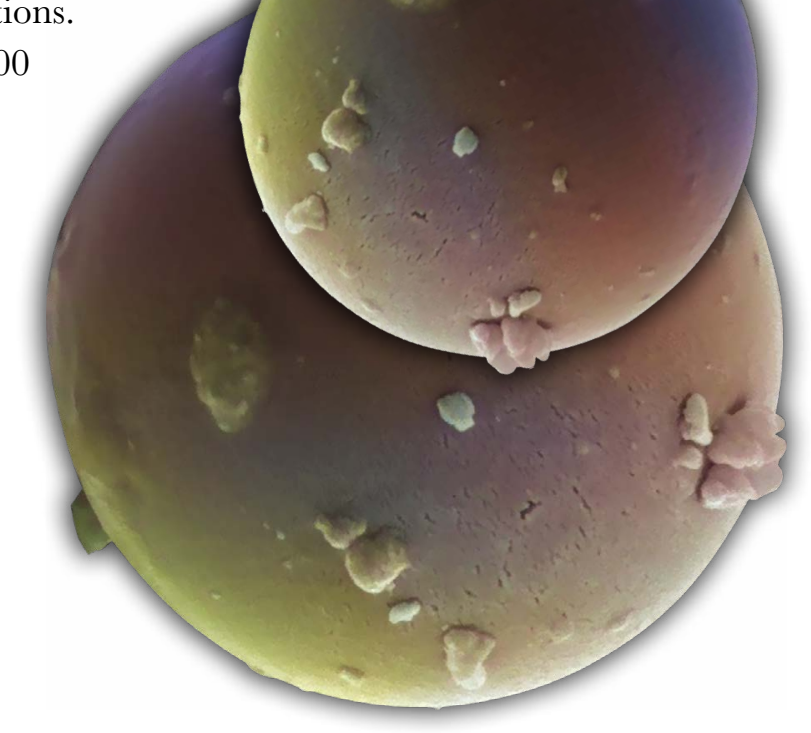


quality. Nanoparticles have been employed as dietary supplements since they cross the digestive tract membranes more easily than larger molecules. They also increase the bioavailability and cell uptake of minerals and reduce mineral antagonism (Abdelnour et al., 2021). Nanoparticles can also be used to diagnose and treat illnesses, administer medication, and apply other compounds by parenteral route (Khin et al., 2012), in which case they must be sterilized in order to avoid endangering the animal's health.

The sterility of a product is the absence of any living microorganism that could endanger health. There are different methods to sterilize nanoparticles, such as sterile filtration, autoclave, ionizing (gamma irradiation) and non-ionizing radiation (ultraviolet, infrared, and microwave irradiation), alongside others such as sterilization by hydrogen peroxide plasma, ethylene oxide, and formaldehyde (Bernal et al., 2021).

Nowadays, sterility assurance levels (SALs) of 10-6 are accepted: a probability of no more than one viable microorganism in a million molecules of the sterilized product (von Woedtke and Krammer, 2008).

In addition, the morphology, the physicochemical properties, and the biological performance of the product must not alter after the sterilization method is applied regardless of the nature of the said method (Fracalossi et al., 2016). Meanwhile, preparation, packaging, and storage conditions must be adequate to prevent contamination and maintain the final productss sterilization efficiency (McKeen, 2018).

\section{STERILIZATION METHODS}

\section{Sterile filtration}

Using 0.2-0.45 $\mu \mathrm{m}$ membrane filters, this technique removes microorganisms found in liquid nanoformulations. This procedure can be useful to sterilize thermosensitive and chemical-sensitive nanosystems. However, it has limitations related to viscosity and filtration, and it can even alter the integrity of the nanoformulation. For this reason, its use should be evaluated for each particular case (Bernal, 2021).

\section{Heat sterilization (autoclave)}

Among the available sterilization methods, the steam method is one of the most widely used due to its low cost and non-toxicity (Adler et al., 1998). The steam sterilization method or autoclave removes polluting agents with high-pressure steam, at a minimum temperature of $120^{\circ} \mathrm{C}$, for approximately 15 to 20 minutes, depending on the size and quantity of the material to be sterilized. Sterilization is achieved when the entire surface reaches a temperature of $121^{\circ} \mathrm{C}$ (Block, 2001; Vetten et al., 2014). To ensure the method's reliability, the temperature, time, and air entrance into the equipment must be controlled (Lerouge, 2010). This method can be used in metal nanoparticles, although the particles may slightly increase in size and crystallize due to the temperature of the autoclave. Nonetheless, steam sterilization has proved to be adequate for mineral nanoparticles, which do not present changes in size or morphology (Santos et al., 2012).

This method can be applied to non-aqueous liquids or dry powder materials. It is not recommended for temperature-sensitive materials (Fracalossi et al., 2016). It destroys or inactivates all microorganisms that are exposed to steam (Stammen et al., 2012). The 
temperature may vary between 120 and $170{ }^{\circ} \mathrm{C}$, with a 20 to 150 -minute exposure (Fracalossi et al., 2016).

Nakamura et al. (2015) tested two sterilization methods (autoclave and gamma irradiation) to analyze the protein breakdown caused by the sterilization process. Since autoclave generated lower protein oxidation than sterilization by gamma irradiation, it was considered adequate for susceptible pharmaceutical and biopharmaceutical products.

Fesharaki et al. (2010) sterilized a Klebsiella pneumoniae culture containing selenium nanoparticles at $121^{\circ} \mathrm{C}, 17 \mathrm{PSI}$, for 20 minutes. No chemical changes were found in the selenium nanoparticles during the sterilization process. When they sterilized diclofenac sodium in an autoclave at a temperature of $123^{\circ} \mathrm{C}, 1.1 \mathrm{~kg} \mathrm{~cm}^{-2}$, in a 25 to 30 -minute range, Roy et al. (2001) observed impurities in the medication; the use of other sterilization methods was therefore recommended. When sterilizing chitosan hydrogel nanoparticles with gamma radiation at 8,12 , and $25 \mathrm{kGy}$, in an autoclave at 100,110 , and $121^{\circ} \mathrm{C}$, during $5,10,15$, and 30 minutes, sterilization by autoclave melted chitosan particles. In contrast, with gamma radiation, the particles kept their original structure (Galante et al., 2016).

\section{Sterilization with ionizing radiation (gamma irradiation)}

Gamma irradiation has been proved to destroy nucleic acids, based on the fact that atoms are ionized and that the free electrons that are created interact with DNA or enzymes or cause the membranes to break, thus destroying microorganisms. This sterilization method uses a photon source (Craven, 2020). The usual sterilization dose is $25 \mathrm{kGy}$ and maximum temperatures fluctuate between 30 and $40{ }^{\circ} \mathrm{C}$. Irradiation usually requires cobalt ${ }^{60}$ because matter absorbs it at a low rate per unit of time (120 kGy-s). Other isotopes, such as cesium ${ }^{137}$ and iridium ${ }^{192}$, are used for industrial and medical materials (Drobny, 2019).

This sterilization method is recommended for thermosensitive medicines and excipients (Domariska et al., 2020). However, irradiation on protein nanoparticles, especially in solution, produced reactive oxygen species capable of changing the protein's structure and inducing degradation effects and a general deterioration of their biological properties (Fazolin et al., 2020).

When materials with added antioxidants are sterilized, gamma sterilization may be detrimental (Yagoubi et al., 1997), besides producing unwanted radicals in polymers (Cottam et al., 2009).

However, gamma-ray sterilization has proved overall to be an effective method and is accepted by the European and US pharmacopeias (Hasanain et al., 2014). Some products currently sold in these countries — such as QuikClot ${ }^{\circledR}$, which helps blood clots form quicker in open wounds - are aluminum silicate nanoparticles sterilized with gamma rays (QuikClot ${ }^{\circledR}, 2021$ ).

\section{Ultraviolet (UV) irradiation sterilization}

Ultraviolet light emits photon energy. When a molecule absorbs this energy, it emits photons, which turn the molecule fluorescent and cause it to get excited. The energy is subsequently released as heat and returns to its natural state, producing biochemical 
changes in the molecule (Gray, 2013). The World Health Organization (WHO) establishes $100-400 \mathrm{~nm}$ wave ranges for ultraviolet radiation and divides them into three bands: UVA (315-400 nm), UBV (280-315 nm), and UVG (100-280 nm) (WHO, 2002).

UV irradiation is an adequate method for the sterilization of polymeric biomedical materials (Sionkowska et al., 2006). Its bactericidal effect takes place at 240-280 nm and depends on the time of exposure. However, Chen et al. (2020) and others have used them at $365 \mathrm{~nm}$.

Several studies have been carried where the large-scale application of UV-ray sterilization was used to eliminate spores of the genus Mycobacterium (Xu et al., 2003). Air pollutants such as formaldehyde and volatile organic compounds (Liu et al., 2019); bacteria such as Escherichia coli, Micrococcus luteus, Pseudomonas fluorescens, and Staphylococcus aureus (Green and Scarpino, 2001); as well as to inactivate airborne viruses (Tseng and Li, 2005) and to sterilize water (Cheng et al., 2020; Timmermann et al., 2015).

Ultraviolet radiation is inexpensive, easy to operate, and allows for quick sterilization. Nonetheless, its effectiveness depends on the sensitivity of bacteria to this radiation, which might be affected by factors such as the environmental $\mathrm{pH}$ and the bacterial growth phase. Finally, information on how this process affects nanomaterials in nanoparticles is scarce since many studies fail to mention either this situation or which wavelength they employed (Bernal et al., 2021).

\section{Sterilization with different gases}

Some advantages of this sterilization method include its environmental safety and its lack of toxic residues. It is used in thermo- and humidity-sensitive compounds (Table 1), ensuring their microbicidal efficiency (Rutala and Weber, 2019).

\section{Sterilization with ethylene oxide and formaldehyde}

Ethylene oxide is used to sanitize medical devices. It is a strong alkaline agent that denatures the nucleic acids and functional proteins of microorganisms. For this reason, it is an excellent sanitizer, although it has the disadvantage of being flammable and explosive, in addition to producing toxic and carcinogenic residues. Formaldehyde is useful for sterilizing highly thermosensitive materials; its main limitations are its toxicity and carcinogenicity (Velten et al., 2014).

\section{SELECTING A STERILIZATION METHOD}

As has been mentioned beforehand, each sterilization method has advantages and disadvantages. Therefore, several factors must be taken into consideration in order to decide which method to use: the physicochemical properties of the materials that constitute

Table 1. Different compounds used in the gas sterilization method Cycle time Temperature Product.

\begin{tabular}{l|l|c|l}
\multicolumn{1}{c|}{ Gas type } & \multicolumn{1}{c|}{ Cycle time } & Temperature $\left({ }^{\circ} \mathbf{G}\right)$ & \multicolumn{1}{c}{ Product } \\
\hline Ethylene oxide & $15 \mathrm{~h}$ & 40 & $\begin{array}{l}\text { Medical instruments, sensitive } \\
\text { to heat }\end{array}$ \\
\hline Peroxide plasma & 28 a $38 \mathrm{~min}$ & 50 & \multicolumn{2}{|c|}{} \\
\hline
\end{tabular}

Fracalossi et al. (2016). 
the nanoparticle, the type of nanoparticle, the complexity of the involved materials, and their rate and physical state, as well as the susceptibility of the encapsulated compound. Sterilization by filtration is recommended for nanoparticles smaller than $200 \mathrm{~nm}$, have low viscosity, and have a low percentage of solids. Radiation is better for other materials, such as those with a low melting point (Bernal et al., 2021). The sterilization process might affect the nanoparticle's structure from the surface to the interior, which could cause it to lose its stability in an aqueous environment and many of its properties and characteristics. In addition, the ease with which each sterilization method is carried out and the availability of the necessary equipment are important factors to consider. However, except gamma radiation, all methods are easy to apply. Finally, terminal sterilization must also be taken into consideration. This type of sterilization refers to the process whereby a product is sterilized within its final packaging or container in order to ensure it is free of microorganisms, as well as of endotoxins and — glucans (Neun and Debrovolskaia, 2019). This process is applied mainly to pharmaceutical products. However, terminal sterilization does not compensate for the lack of control and good practices in the previous sterilization process. The most commonly used methods include humid heat sterilization, irradiation, and the use of ethylene oxide. Sterilization methods require validation which involves biosafety, structural characterization, and toxicity tests (Bernal et al., 2021).

\section{CONGLUSIONS}

Livestock production faces challenges when improving animal productivity and offering high-quality products without increasing consumer costs. Nanotechnology opens great possibilities in this domain, since it improves productive behavior and nutrient availability; moreover, it is employed in veterinary medicine. Therefore, when nanoparticles need to be sterilized, the method of choice will depend on the size, quantity, and type of product,

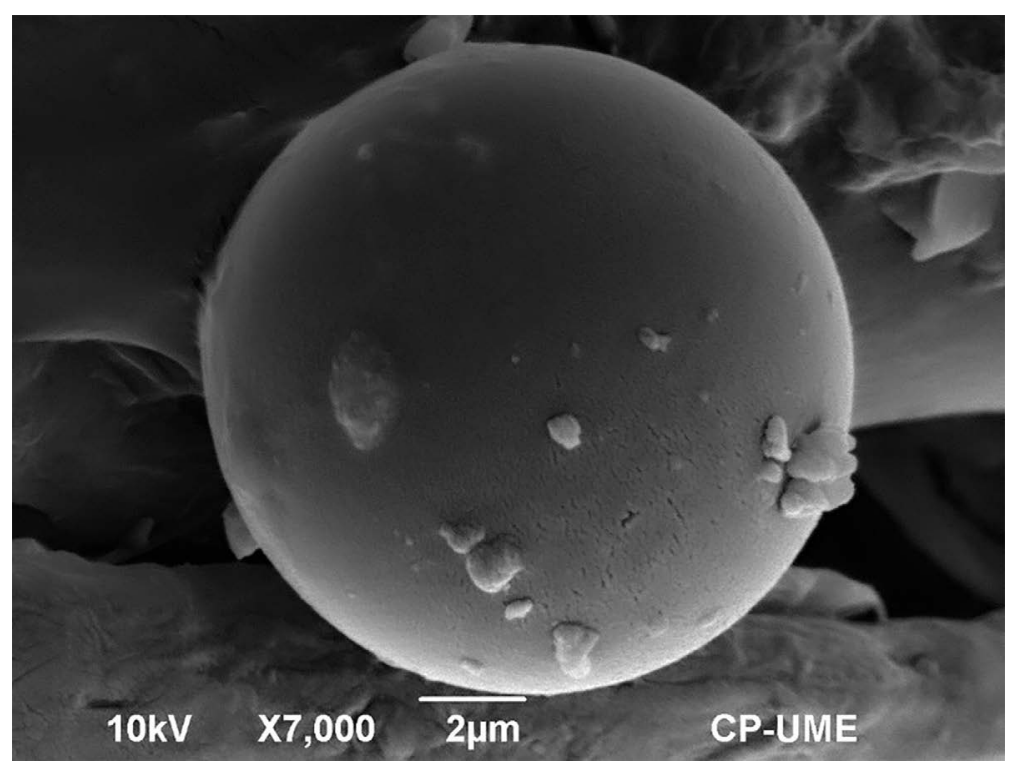

Figure 1. Nanosphere characterized by the Unidad de Microscopía Electrónica del Colegio de Postgraduados (CP-UME), Montecillo, Texcoco, Mexico. 
since each method requires specific conditions, such as temperature and time of exposure, which can modify the physicochemical structure of the final product. The packaging type and material must also be considered because it might cause unwanted reactions if it is not sterilized. Hence the importance of terminal sterilization.

\section{REFERENGES}

Abdelnour, S.A., Alagawany, M., Hashem, N.M., Farag, M.R., Alghamdi, E.S., Hassa, F.UI., Bilal, R.M., Elnesr, S.S., Dawood, M.A.O., Nagadi, S.A., Elwan, H.A.M., \& ALmasoudi, A.G., Attia, Y.A. (2021). Nanomaterials: Fabrication methods, benefits and hazards, and their application in ruminants with special reference to selenium and zinc particles. Animals 2021, 11, 1916. https://doi.org/10.3390/anil 1071916

Adler, S., Scherrer, M., \& Daschner, F. D. (1998). Costs of low-temperature plasma sterilization compared with other sterilization methods. Journal of Hospital Infection 4O(2):125-134. https://doi.org/10.1016/ S0195-6701(98)90091-3

Bernal, G.S.A., Del Prado, A.M.L., Caballero, F.I.H., Giraldo, G.D.M., Figueroa, G.G., Reyes, H.O.D., González, del C.M., González, T.M., Cortés, \& H., Leyva, G.G. (2021). Insights into terminal sterilization processes of nanoparticles for biomedical applications. Molecules 2021, 26, 2068. https// doi.org/10.3390/molecules26072068

Block, S. S. (2001). Disinfection by ultraviolet irradiation. Disinfection, Sterilization, and Preservation. 5th ed. Lippincott, Williams E Wilks. Lea and Febinger, Philadelphia, PA. pp. 523-583.

Bunglavan, S.J., Garg, A.K., Dass, R.S. \& Shrivastava, S. (2014). Use of nanoparticles as feed additives to improve digestion and absorption in livestock. Livestock Research International 2(3):36-47.

Chen, W., Ko, G., Chang, K. \& Chen, C. (2020). Influences of processing and sterilizing strategies on reduced silver nanoparticles in poly (vinyl alcohol) electrospun membranes: Optimization and preservation of antibacterial activity. Materials Chemistry and Physics, 254:1-11. https://doi.org/10.1016/j. matchemphys.2020.

Cheng, G., Li, Z., Sun, L., Li, Y. \& Fu, J. (2020). Application of microwave/electrodeless discharge ultraviolet/ ozone sterilization technology in water reclamation. Process Safety and Environmental Protection 138:148156. https://doi.org/10.1016/j.psep.2020.03.015

Cottam, E., Hukins, D. W. L., Lee, K., Hewitt, C. \& Jenkins, M. J. (2009). Effect of sterilisation by gamma irradiation on the ability of polycaprolactone (PCL) to act as a scaffold material. Medical Engineering and Physics 31:221-226. https://doi.org/10.1016/j.medengphy.2008.07.005

Craven, E. (2020). An alternative maximum dose testing method for electron beam sterilization processes. Radiation Physics and Chemistry 173:1-2. https://doi.org/10.1016/j.radphyschem.2020.108937

Domariska, L.M., Oledzka, E. \& Sobczak, M. (2020). Sterilization process of polyester based anticancerdrug delivery systems. International Journal of Pharmacology 587 (2020) 119663. doi:10.1016/ ijpharm.2020.119663

Drobny,J. G. (2019). 1. Introduction. Fundamentals of Radiation Chemistry and Physics. In: Ionizing Radiation and Polymers: Principles, Technology, and Applications. 1-10. https://doi.org/10.7591/9780801459429-004.

Fazolin, G. N., Varca, G. H. C., Freitas, L. F. De, Rokita, B., Kadlubowski, S, \& Lugão, A. B. (2020). Simultaneous intramolecular crosslinking and sterilization of papain nanoparticles by gamma radiation. Radiation Physics and Chemistry, 171:1-7. https://doi.org/10.1016/j.radphyschem.2020.

Fesharaki, P. J., Nazari, P., Shakibaie, M., Rezaie, S., Banoee, M., Abdollahi, M. \& Shahverdi, A. R. (2010). Biosynthesis of selenium nanoparticles using Klebsiella pneumoniae and their recovery by a simple sterilization process. Brazilian Journal of Microbiology 47(2):461-466. https://doi.org/10.1590/S151783822010000200028

Fracalossi, C., Corte, R., Dua, K., Satiko, I., Jesus, T. De. \& Pinto, A. (2016). Impact of sterilization methods on electrospun scaffolds for tissue engineering. European Polymer Journal, 82:181-195. https://doi. org/10.1016/j.eurpolymj.2016.07.016

Galante, R., Rediguieri, C. F., Kikuchi, I. S., Vasquez, P. A. S., Colaço, R., Serro, A. P., \& Pinto, T. J. A. (2016). About the sterilization of chitosan hydrogel nanoparticles. PLoS ONE 11(12):1-18. https://doi. org/10.1371/journal.pone.0168862

Gray, N. F. (2013). Ultraviolet disinfection. In: Microbiology of Waterborne Diseases: of the irradiation Microbiological Aspects and Risks: 2nd ed. Percival, S.L., Williams, D.W., Gray, N.F., Yates, M.V. \& Chalmers, R.M. Elsevier. pp. 617-630. https://doi.org/10.1016/B978-0-12-415846-7.00034-2

Green, C. F. \& Scarpino, P. V. (2001). The use of ultraviolet germicidal irradiation(UVGI) in disinfection of airborne bacteria. Environmental Engineering and Policy 3(1):101-107. https://doi.org/10.1007/s100220100046 
Hasanain, F., Guenther, K., Mullet, W.M. \& Craven, E. (2014). Gamma sterilization of pharmaceuticals - A review of the irradiationof excipients, active pharmaceutical ingredients, and final drug product formulations. PDA Journal of Pharmaceutical Science and Technology 68:113-137. doi:10.5731/ pdajpst.2014.00955

Khin, M.M., Nahir, A.S., Babu, V.J., Murugan, R. \& Ramakrishna, S.A. (2012). A review on nanomaterials for environmental remedation. Energy Environmental Science 5:8075-8109. DOI:10.1030/c2ee21818f

Lerouge, S. (2010). Sterilisation and cleaning of metallic biomaterials. Metals for Biomedical Devices 16:405-428. https://doi.org/10.1533/9781845699246.3.303

Liu, C. Y., Tseng, C. H., Wang, H. C., Dai, C. F. \& Shih, Y. H. (2019). The study of an ultraviolet radiation technique for removal of the indoor air volatile organic compounds and bioaerosol. International Journal of Environmental Research and Public Health, 16(14):2-16. https://doi.org/10.3390/ijerph16142557

McKeen, L (2018). Introduction to Food Irradiation and Medical Sterilization. The Effect of Sterilization Methods on Plastics and Elastomers. Andrew, W. ed. Elsevier. pp. 1-468 https://doi.org/10.1016/b978-0-12-8145111.00001-9

Nakamura, K., Kiminami, H., Yamashita, A., Abe, Y., Yoshino, K., \& Corporation, T. (2015). Assessment of the effects of sterilization methods on protein drug stability by elucidating decomposition mechanism and material analysis. International Journal of Pharmaceutics, 484(1-2):51-56. https://doi.org/10.1016/j. ijpharm.2015.02.020

OMS (Organización Mundial de la Salud). (2002). Índice UV solar mundial. Guía Práctica. ISBN 924159007 6. pp 1.36. 2002. http://www.who.int/uv

Neun, B.W. \& Debrovolskaia, M.A. (2019). Understanding endotoxin and $\beta$-glucan contamination in nanotechnology-based drug products. Chapter 12. In: Endotoxin detection and control in pharma, limulus and mammalian systems. Williams, K.L. ed. Springer Nature. Switzerland. pp.481-496.

QuikClot $^{\circledR}$. 2021. Proprietary hemosttatic technology. https://quikclot.com

Roy, J., Islam, M., Khan, A. H., Das, S. C., Afhteruzzaman, M., Deb, A. K. \& Mahbub Alam, A. H. (2001). Diclofenac sodium injection sterilized by autoclave and the occurrence of cyclic reaction producing a small amount of impurity.Journal of Pharmaceutical Sciences 90(5):541-544. https://doi.org/10.1002/15206017(200105)90:5<541::AID-JPS1011>3.0.CO;2-O

Rutala, W. A., \& Weber, D. J. (2019). Disinfection, sterilization, and antisepsis: An overview. American Journal of Infection Control 47:A3-A9. https://doi.org/10.1016/j.ajic.2019.01.018

Santos, C., Gomes, P.S., Duarte, J.A., Franke, R.P., Almeida, M.M., Costa, M.E.V., \& Fernandes, M.H. (2012). Relevance of the sterilization-induced effects on the properties of different hydroxyapatite nanoparticles and assessment of the osteoblastic cell response. Journal of the Royal Society, Interface 9:3397-3410. doi:10.1098/rsif.2012.0487

Sionkowska, A., Kaczmarek, H. \& Wisniewski, M. (2006). The influence of UV irradiation on the surface of chitosan films, Surface Science 600:3775-3779. https://doi.org/10.1016/j.susc.2006.01.090

Stammen, E., Thiele, R., Stefan, B., Cornelia, B., Dilger, K., \& Jochen, B. (2012). Withstanding frequent steam sterilisation: Innovative technique to bond glass and stainless steel composites in biotechnology and endoscopic medicine, International Journal of Adhesion and Adhesives 33:15-25. https://doi.org/10.1016/j. ijadhadh.2011.10.005

Timmermann, L. F., Ritter, K., Hillebrandt, D., \& Küpper, T. (2015). Drinking water treatment with ultraviolet light for travelers - Evaluation of a mobile lightweight system. Travel Medicine and Infectious Disease 13(6):466-474. https://doi.org/10.1016/j.tmaid.2015.10.005

Tseng, C. C., \& Li, C. S. (2005). Inactivation of virus-containing aerosols by ultraviolet germicidal irradiation. Aerosol Science and Technology, 39(12), 1136-1142. https://doi.org/10.1080/02786820500428575

Vetten, M. A., Yah, C. S., Singh, T., \& Gulumian, M. (2014). Challenges facing sterilization and depyrogenation of nanoparticles: Effects on structural stability and biomedical applications. Nanomedicine: Nanotechnology, Biology, and Medicine 10(7):1391-1399. https://doi.org/10.1016/j.nano.2014.03.017

von Woedtke, T., \& Krammer, A. (2008). The limits of sterility assurance. GMS Krankenhaushygiene Interdisziplinär 3(3):1-10. https://doi.org/10.1007/s00216-004-3039-6

Xu, P., Peccia, J., Fabian, P., Martyny, J. W., Fennelly, K. P., Hernandez, M. \& Miller, S. L. (2003). Efficacy of ultraviolet germicidal irradiation of upper-room air in inactivating airborne bacterial spores and mycobacteria in full-scale studies. Atmospheric Environment 37(3):405-419. https://doi.org/10.1016/ S1352-2310(02)00825-7

Yagoubi, N., Boucherie, P., \& Ferrier, D. (1997). Radiosterilization and steam autoclaving sterilization effects on phosphite antioxidant stability. Nuclear Instruments and Methods in Physics Research Section B: Beam Interactions with Materials and Atoms 131(1-4):398-404. https://doi.org/10.1016/S0168-583X(97)00192-4 